\title{
Análise da autorregeneração de matrizes cimentícias através de diferentes métodos de inserção de soluções químicas e bacterianas.
}

\author{
A. Loeff ${ }^{1}$, F. Pacheco ${ }^{2 *}$, V. Müller ${ }^{3}$, H. Z. Ehrenbring ${ }^{2}$, R. Christ $^{2}$, R. C. E. Modolo ${ }^{4}$, B. F. \\ Tutikian $^{2}$ \\ *Autor de Contacto: fernandapache@unisinos.br \\ ${ }^{1}$ Engenheira Civil, Universidade do Vale do Rio dos Sinos, São Leopoldo, Brasil \\ ${ }^{2}$ Doutor(a) em Engenharia Civil, itt Performance, Universidade do Vale do Rio dos Sinos, São Leopoldo, Brasil \\ ${ }^{3}$ Engenheiro Civil, itt Performance, Universidade do Vale do Rio dos Sinos, São Leopoldo, Brasil \\ ${ }^{4}$ Doutora em Ciências e Engenheira do Ambiente, Universidade do Vale do Rio dos Sinos, São Leopoldo, Brasil
}

\begin{abstract}
RESUMO
Este estudo analisou o potencial de cicatrização do concreto quando do uso de soluções bacterianas e soluções químicas, avaliando diferentes materiais que podem ser empregados para seu encapsulamento. Para encapsular os agentes, foram empregadas argila expandida e perlita expandida. Para analisar a eficácia da cicatrização, realizaram-se as técnicas de análise visual através de microscópio óptico de alta precisão e microtomografia 3D. Os resultados apontaram para um melhor desempenho do traço BAC.AE, utilizando solução bacteriana encapsulada em argila expandida, que foi capaz de cicatrizar fissuras de até $0,57 \mathrm{~mm}$, tendo os traços BAC.PE, solução bacteriana encapsulada em perlita expandida, e SS, solução química adicionada no momento de moldagem em substituição à água, cicatrizado fissuras de $0,16 \mathrm{~mm}$ e $0,29 \mathrm{~mm}$ respectivamente.
\end{abstract}

Palabras clave: Bioconcreto; Autorregeneração; Autocicatrização; Fissuras; Bactérias. 


\begin{abstract}
This study analyzed the healing potential of concrete when using bacterial and chemical solutions, evaluating different materials that can be used for its encapsulation. To encapsulate the agents, expanded clay and expanded perlite were used. To analyze the effectiveness of healing, visual analysis techniques were performed using a high-precision optical microscope and 3D microtomography. The results pointed to a better performance of the BAC.AE mixture, using bacterial solution encapsulated in expanded clay, which was able to heal cracks of up to $0.57 \mathrm{~mm}$, having the mixture BAC.PE, bacterial solution encapsulated in expanded perlite, and SS , chemical solution added at the time of mixturing to replace water, healed cracks of $0.16 \mathrm{~mm}$ and $0.29 \mathrm{~mm}$ respectively.
\end{abstract}

Palabras clave: Bioconcrete; Self-healing; Fissures; Bacteria.

\title{
RESUMEN
}

Este estudio analizó el potencial de curación del hormigón al utilizar soluciones químicas y bacterianas, evaluando diferentes materiales que se pueden utilizar para su encapsulación. Para encapsular los agentes se utilizaron arcilla expandida y perlita expandida. Para analizar la efectividad de la curación, se realizaron técnicas de análisis visual utilizando un microscopio óptico de alta precisión y microtomografía 3D. Los resultados apuntaron a un mejor desempeño de la mezcla BAC.AE, utilizando solución bacteriana encapsulada en arcilla expandida, que fue capaz de cicatrizar grietas de hasta $0.57 \mathrm{~mm}$, teniendo las mezclas BAC.PE, solución bacteriana encapsulada en perlita expandida, y SS , solución química agregada en el momento de la mezcla para reemplazar el agua, cicatrizaron grietas de $0.16 \mathrm{~mm}$ y $0.29 \mathrm{~mm}$ respectivamente.

Palabras clave: Biohormigón; Autorregeneración; Autocuración; Fisuras; Bacterias. 


\section{INTRODUÇÃO}

$\mathrm{O}$ concreto apresenta inúmeras vantagens que conduzem à sua elevada aplicabilidade (GONSALVES, 2011; SEIFAN; SAMANI; BERENJIAN, 2016), todavia, o material sofre deterioração. Percebe-se que a sustentabilidade das estruturas não pode ser alcançada se necessitarem de constantes reparos e ajustes. Desta forma, é fundamental que haja um aprimoramento na durabilidade dos concretos, especialmente nos países de terceiro mundo, onde mais costumam ocorrer as falhas prejudiciais da indústria da construção (CHEMROUCK, 2015). A durabilidade do concreto pode ser descrita como sua capacidade de resistir à deterioração, sendo essa degradação proveniente da exposição ao clima ou da abrasão da superfície (ACHAL et al, 2011), considerando-se que existem diferentes condições de exposição ambiental (GJORV, 2016). Atualmente, as maiores responsáveis pela degradação do concreto são as fissuras, devido à diversas causas. Visto isso, ao longo dos anos, vêm surgindo inúmeras inovações neste contexto, entra elas o SHC - Self Healing Concrete (AZARSA et al, 2019), objeto de estudo deste trabalho. A ideia principal do concreto autorregenerante é que se deve fornecer as condições necessárias para que os agentes presentes na matriz cimentícia possam preencher as fissuras uma vez que elas tenham ocorrido. Nas últimas décadas, pesquisas nessa área apontaram muitas estratégias inovadoras (WU et al., 2012), dentre elas, uso de agentes de cicatrização em fibras ocas, seu micro-encapsulamento (WHITE et al, 2001), inserção de agentes expansivos e aditivos minerais (KISHI; AHN, 2010), materiais de memória de forma (ABDULRIDHA et al., 2012) e soluções bacterianas (KRISHNAPRIYA; BABU; ARULRAJ, 2015).

$A$ adição de soluções bacterianas em matrizes cimentícias tem se mostrado uma possibilidade promissora e sustentável (KRISHNAPRIYA; BABU; ARULRAJ, 2015). Esta técnica de autocura se dá pela adição de cápsulas de algum material específico contendo as bactérias, que podem permanecer inativas durante décadas, juntamente com um nutriente, como o lactato de cálcio. Dessa forma, quando as cápsulas se rompem com a fissuração do concreto e há umidade, as bactérias se tornam ativas e produzem calcita (PATEL, 2015). As bactérias utilizadas devem ter capacidade de suportar a alta alcalinidade do cimento e a pressão de compressão interna da matriz cimentícia onde está inserida. Também dever ser fornecida uma fonte de nutriente para a alimentação das bactérias (LI; HERBERT, 2012).

Além da solução bacteriana, a solução química também tem se mostrado uma alternativa eficaz para o fechamento de fissuras na matriz do concreto (ALGHAMRI; KANELLOPOULOS; ALTABBAA, 2016). Nos estudos realizados por Huang et al. (2011) e Pelletier et al. (2011) foram utilizadas cápsulas esféricas para encapsular uma solução de silicato de sódio, que quando rompidas liberaram a solução na matriz, onde ocorreu a reação com hidróxido de cálcio, formando silicato de cálcio hidratado $(\mathrm{C}-\mathrm{S}-\mathrm{H})$ que curou a fissura do concreto.

Dados os atuais e complicados processos de encapsulamento em desenvolvimento, é notável a improbabilidade de suas aplicações em escala real. Nota-se uma escassez de estudos que comparem diferentes métodos de encapsulamento para as soluções bacterianas e químicas inseridas na matriz cimentícia, portanto, este estudo conduz uma análise comparativa, com encapsulamento de bactérias em perlita e argila expandida, e também a eficácia da utilização de silicato de sódio diretamente na água de amassamento.

\section{FISSURAÇÃO E AUTOCICATRIZAÇÃO EM ESTRUTURAS DE CONCRETO ARMADO}

As fissuras são consideradas as manifestações patológicas características das estruturas de concreto e chamam a atenção para o fato de que algo de anormal está acontecendo (BIANCHINI, 2008). Lottermann (2013) explica que algumas das causas mais usuais do fissuramento das 
estruturas são: cura mal realizada; retração; variação de temperatura; agressividade ambiental; carregamento; erros de execução e de detalhamento de projeto e recalques dos apoios. As fissuras podem ser divididas entre as que se originam no estado fresco e aquelas que surgem no concreto após seu endurecimento. Podem ainda ser motivadas por mais de uma causa simultaneamente (GUPTA; PANG; KUA, 2017). Considerando o efeito que as fissuras exercem na durabilidade, suas aberturas limites são abordadas em normas nacionais e internacionais (CARMONA FILHO; CARMONA, 2013). Na norma brasileira, por exemplo, as fissuras permitidas encontram-se na faixa de valor entre 0,2 e 0,4mm (ASSOCIAÇÃO BRASILEIRA DE NORMAS TÉCNICAS, 2014).

Por mais que estudos anteriores tenham sido conduzidos nessa temática, o marco inicial mais aceito na literatura, e que mudou a postura acerca do tema, foi a pesquisa de Dry, em 1994. Os estudos conduzidos por Dry (1994 apud BIANCHIN, 2018) propuseram o uso de polímeros encapsulados para obter o concreto autocicatrizante. Além disso, foi proposto não apenas a descrição dos fenômenos envolvidos e suas possíveis causas, mas também o uso intencional dessas propriedades com a finalidade de obter um material mais durável.

Desde 2005, dois comitês técnicos já foram criados para o estudo dos fenômenos de autocicatrização em matérias de base cimentícia (CAPPELLESSO, 2018). Parece haver um consenso no meio técnico de que concretos autocicatrizantes sejam aqueles com o fechamento das fissuras e concretos autorregenerantes como os que envolvem ainda a recuperação de propriedades mecânicas (PACHECO, 2020). Há ainda a diferenciação relacionada aos mecanismos utilizados para tal, divididos entre autógenos e autônomos. Autógeno refere-se à quando o processo de self-healing utiliza materiais que poderiam estar presentes na composição do concreto e que não são especificamente utilizados para a autocicatrização. Já o procedimento autônomo considera o uso de materiais que não seriam encontrados na composição e foram apenas adicionados para este fim. Os mecanismos autógenos não foram estudados nessa pesquisa, sendo amostras com pozolanas ou cimento.

A cicatrização por mecanismos autônomos são as baseadas em microcápsulas preenchidas com agentes cicatrizantes ou tubos vasculares (VAN TITTELBOOM et al., 2011). Entre os agentes de cicatrização têm-se soluções químicas, soluções bacterianas, polímeros superabsorventes (PSA), aditivos redutores de permeabilidade, expansivos, entre outros.

O encapsulamento de soluções químicas corresponde a impregnação de agregados leves e porosos com alguma solução química (ALGHAMRI; KANELLOPOULOS; AL-TABBAA, 2016). Souradeep e Kua (2016) explicam que os agentes são liberados pela ruptura das cápsulas. Após liberação, os agentes cicatrizantes penetram na fissura por meio de capilaridade. Souradeep e Kua (2016) afirmam que a estratégia de encapsulamento é capaz de aumentar a vida útil de agentes químicos ou biológicos de cura, garantindo recuperação e maior durabilidade ao concreto. Em termos das soluções químicas, nota-se o uso de silicato de sódio como uma possibilidade (MANOJ-PRABAHAR et al., 2017).

A aplicação de bactérias para remediação de fissuras consiste na produção de calcita $(\mathrm{CaCO} 3)$ que é inócua ambientalmente, quando comparada a polímeros sintéticos usados para reparos de concreto atualmente (RAMACHANDRAN; RAMAKRISHNAN; BANG, 2001). Sobre elas, há algumas diferentes abordagens no uso, podendo ser utilizada a precipitação de carbonato de cálcio através da hidrólise bacteriana da ureia (ELZÉBIO; ALVES; FERNANDES, 2017), assim como a incorporação de esporos bacterianos e compostos orgânicos no concreto (SCHWANTESCEZARIO et al., 2017).

Um fator que pode afetar as bactérias é o pH muito alcalino do concreto. Outro aspecto é que as células da bactéria podem ser destruídas durante o processo de hidratação do cimento. Por isso, o encapsulamento é uma estratégia de proteção desses seres (JONKERS; THIJSSEN, 2010). 
Tabela 1. Variáveis do estudo.

\begin{tabular}{|c|c|c|c|c|c|}
\hline Traço & Cimento & Areia & Perlita & a/c & Agente cicatrizante \\
\hline Referência & 1,00 & 1,00 & - & 0,36 & - \\
\hline BAC.PE & 1,00 & 0,7 & 0,064 & 0,36 & B.subtilis \\
\hline BAC.AE & 1,00 & 0,7 & 0,147 & 0,36 & B.subtilis \\
\hline SS & 1,00 & 1,00 & - & 0,18 & Silicato de sódio \\
\hline
\end{tabular}

\section{MATERIAIS E MÉTODOS}

A Tabela 1 apresenta a composição dos traços realizados nessa pesquisa. $O$ traço referência é baseado no estudo de Schwantes-Cezario et al. (2019). Nos traços BAC.AE e BAC.PE foi feita a substituição de $30 \%$ da massa de areia pelo volume correspondente de argila expandida (AE) e de perlita expandida (PE), respectivamente. No traço SS foi utilizado aditivo superplastificante Powerflow 3100 para adequação da fluidez, sendo o teor utilizado de $0,89 \%$ em relação à massa de cimento. Em cada um dos traços foram realizados os ensaios de compressão, tração na flexão (para indução da fissura) análise visual e microtomografia 3D.

\subsection{Materiais}

O cimento utilizado no estudo foi o cimento Portland tipo CP 11-F-40, da marca Itambé, sem pozolanas. A areia utilizada neste estudo foi areia quartzosa extraída de rios. A massa unitária obtida da areia foi de $1.592,16 \mathrm{~kg} / \mathrm{m} 3$ e a massa específica de $2.427,36 \mathrm{~kg} / \mathrm{m} 3$. A obtenção da granulometria da areia, apresentada na Figura 1, foi realizada através de ensaios de acordo com a NBR NM 248 (ASSOCIAÇÃO BRASILEIRA DE NORMAS TÉCNICAS, 2003).

Como solução química foi utilizado silicato de sódio neutro, em estado líquido, um composto de fórmula $\mathrm{Na} 2 \mathrm{SiO} 3$, devido a sua alta compatibilidade com matrizes cimentícias, sendo ele diluído no teor de $50 \%$ em água deionizada, motivo pelo qual a relação água/cimento deste traço é metade dos anteriores. A espécie de bactéria utilizada na solução bacteriana do programa experimental é a Bacillus subtilis AP 91, oriunda da unidade de Campinas da EMBRAPA (Empresa Brasileira de Pesquisa Agropecuária). Os procedimentos de verificação da curva de crescimento e preparo constam no estudo de Pacheco (2020).

A PE foi fornecida pela empresa Pervale Minerais, com granulometria entre 2 e $4 \mathrm{~mm}$, tendo sido peneirada antes da utilização para adequação à esta faixa granulométrica. A determinação da massa unitária foi realizada para o material em sua condição natural e para o material impregnado com a solução bacteriana e revestido com cimento, obtendo valores de $128,43 \mathrm{~kg} / \mathrm{m}^{3}$ e 328,52 $\mathrm{kg} / \mathrm{m}^{3}$, respectivamente. A determinação da granulometria da perlita (apresentada na Figura 2) foi realizada de acordo com a NBR NM 248 (ASSOCIAÇÃO BRASILEIRA DE NORMAS TÉCNICAS, 2003). 


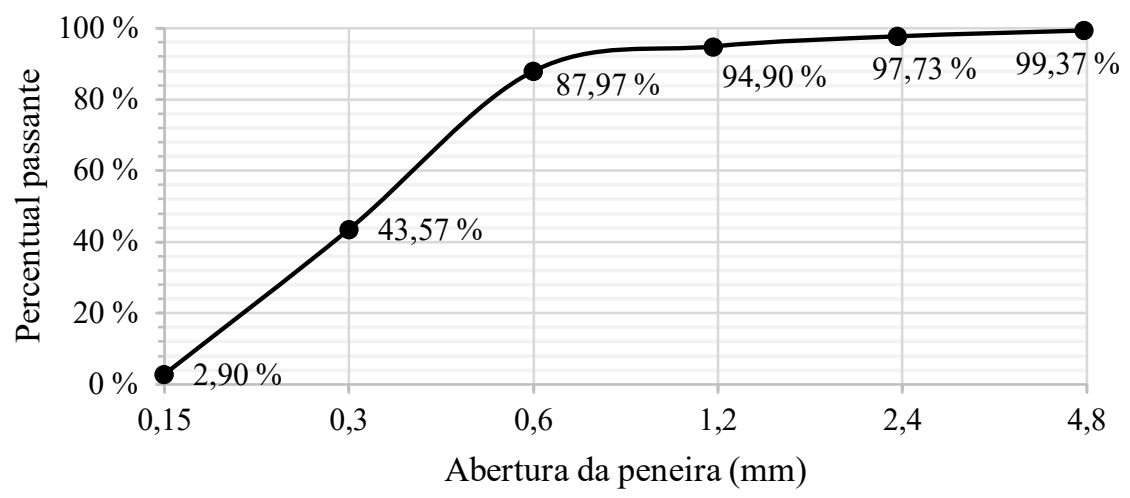

Figura 1. Distribuição granulométrica da areia.

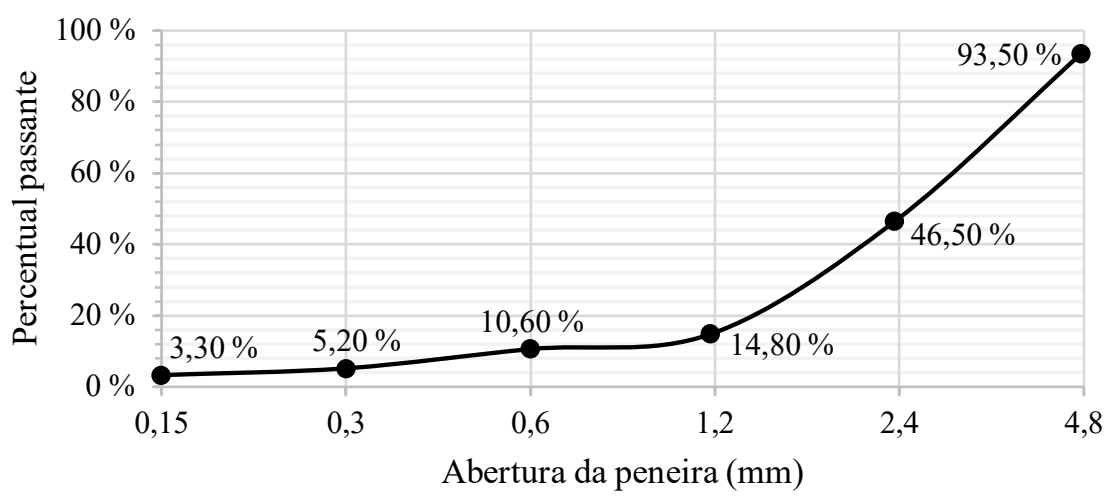

Figura 2. Distribuição granulométrica da perlita expandida.

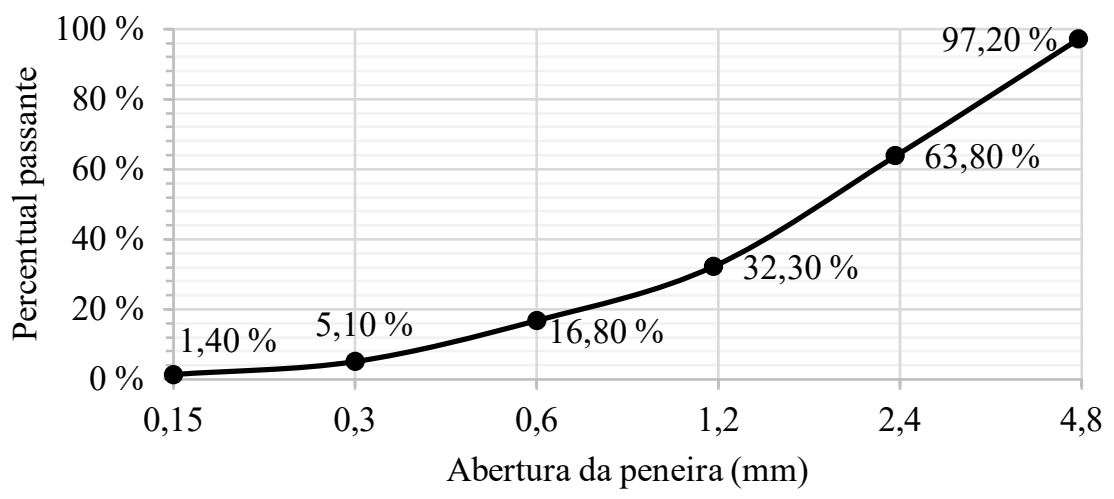

Figura 3. Distribuição granulométrica da argila expandida.

A AE utilizada foi do tipo 0500, adquirida com a empresa Global Minérios, com granulometria entre 2 e $4 \mathrm{~mm}$. Para sua caracterização foram realizados os ensaios de massa unitária e da determinação granulométrica (ver Figura 3), de acordo com as normas NBR NM 45 (ASSOCIAÇÃO BRASILEIRA DE NORMAS TÉCNICAS, 2006) e NBR NM 248 (ASSOCIAÇÃO BRASILEIRA DE NORMAS TÉCNICAS, 2003), respectivamente. A determinação da massa unitária foi realizada em condição natural e para o material impregnado com a solução bacteriana e revestido com cimento, com valores de $930,39 \mathrm{~kg} / \mathrm{m}^{3}$ e 1395,48 $\mathrm{kg} / \mathrm{m}^{3}$, respectivamente. 


\subsection{Métodos}

Para as análises realizadas, foram moldados um total de 27 corpos de prova cilíndricos $(50 \mathrm{x}$ $100 \mathrm{~mm})$ e 9 corpos de prova prismáticos $(60 \times 60 \times 180 \mathrm{~mm})$, conforme NBR 5738 (ASSOCIAÇÃO BRASILEIRA DE NORMAS TÉCNICAS, 2015), respectivamente, e 3 corpos de prova cilíndricos $(8 \times 30 \mathrm{~mm})$. As amostras de formato prismático foram armadas com uma barra de aço CA 60 de $5 \mathrm{~mm}$ de diâmetro, posicionadas a $2 \mathrm{~cm}$ da base, para que a amostra não sofresse ruptura frágil. Após a desforma, as amostras foram curadas em câmara com umidade e temperatura controlada, conforme a NBR 5738 (ASSOCIAÇÃO BRASILEIRA DE NORMAS TÉCNICAS, 2015).

\subsubsection{Encapsulamento da solução bacteriana}

O procedimento com a solução bacteriana envolveu imersão das cápsulas na solução e sua saturação em dessecador à vácuo (SISOMPHON; COPUROGLU; FRAAIJ, 2011). Após finalizada a impregnação, a $\mathrm{PE}$ e a $\mathrm{AE}$ foram colocadas em bandejas e encaminhadas à estufa por 48 horas à $45^{\circ} \mathrm{C}$, como realizado por Zhang et al. (2017). Juntamente com a solução bacteriana foi disposto o nutriente de lactato de cálcio. Mais detalhes desse procedimento experimental podem ser verificados no estudo de PACHECO (2020).

\subsubsection{Ensaios}

A resistência à compressão do concreto foi obtida pela NBR 5739 (ASSOCIAÇÃO BRASILEIRA DE NORMAS TÉCNICAS, 2018). Para formação de fissuras, as amostras prismáticas foram submetidas ao ensaio de tração na flexão por 3 pontos, pela NBR 13279 (ASSOCIAÇÃO BRASILEIRA DE NORMAS TÉCNICAS, 2005). As análises visuais da cicatrização ocorreram na idade inicial e aos 7, 14 e 35 dias.

Foi realizado ensaio de microtomografia 3D para verificar a distribuição de vazios no material. Para este ensaio foram utilizadas amostras de formato cilíndrico de $8 \times 30 \mathrm{~mm}$, sendo analisada uma amostra por traço.

\section{ANÁLISE DOS RESULTADOS}

Os resultados de resistência à compressão, da análise visual e da microtomografia 3D são apresentados nos itens a seguir.

\subsection{Resistência mecânica à compressão}

Os resultados obtidos para resistência à compressão são apresentados na Figura 4. Pode-se perceber, que a resistência à compressão se manteve muito semelhante ao longo do tempo, o que pode decorrer do cimento utilizado, que já apresenta alta resistência logo nas primeiras idades. A maior diferença encontrada se dá no traço SS, com uma diferença de 4,7 $\mathrm{MPa}(11,63 \%)$ de resistência, entre os 14 e 35 dias. O SS pode ter gerado nesse período C-S-H decorrente da sua ativação, por não depender da fissuração para atuar (GIANNAROS; KANELLOUPOULOS; ALTABBAA, 2016)

Também é importante observar que houve uma diferença expressiva na resistência ao comparar os diferentes traços, sendo observado que o traço BAC.AE adquiriu uma resistência muito maior do que os outros dois traços utilizados, com até $12,7 \mathrm{MPa}$ de diferença aos 35 dias. É possível que esta diferença ocorra pois a massa unitária da perlita é menor que a da argila, sendo que ambas foram adicionadas às misturas em granulometrias semelhantes. 


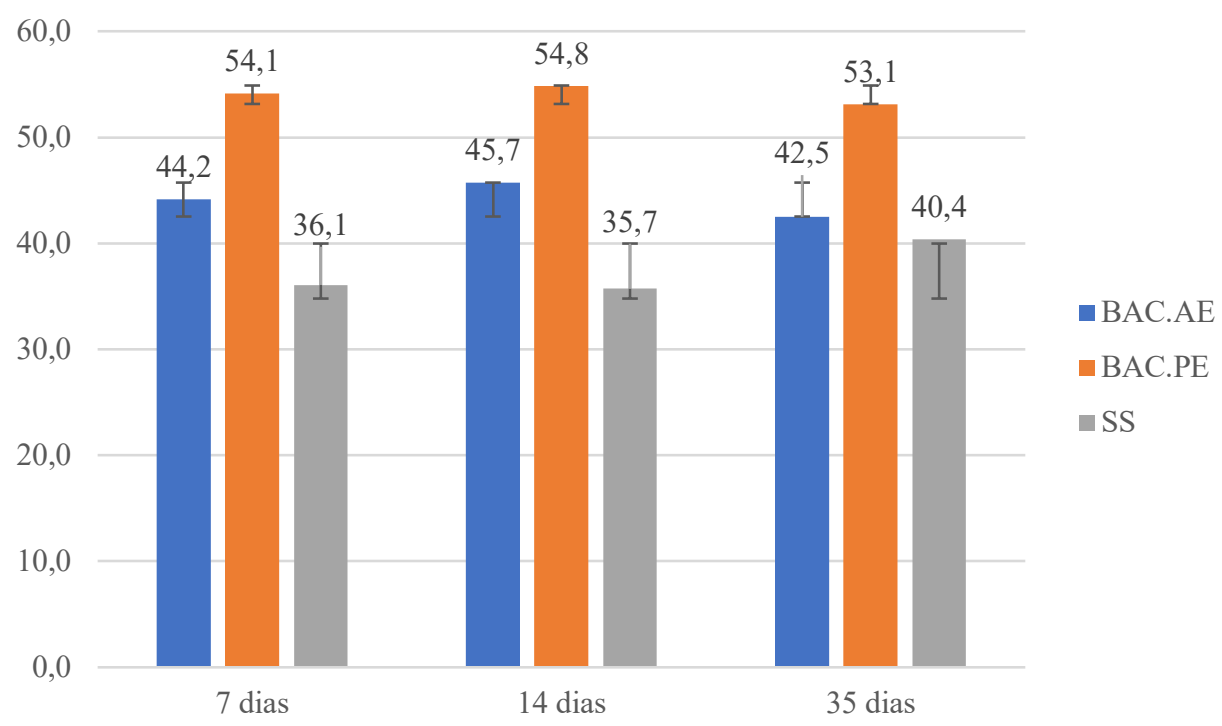

Figura 4. Resistência à compressão média das amostras.

Conforme estudo realizado por Schwantes-Cezario, Nogueira e Toralles (2017), com traço usado nesse estudo, a resistência a compressão encontrada nas amostras deveria ter um valor médio de $65 \mathrm{MPa}$, porém, este valor não foi atingido em função da inserção de agregado leve na mistura, uma vez que, segundo Jonkers (2011), o uso deste tipo material reduz a resistência à compressão. Porém, este parâmetro não pode ser utilizado ao avaliar o traço SS, uma vez que ele não leva agregados leves em sua composição, ficando assim, o motivo do decréscimo em sua resistência associados à possível hidratação não completa do cimento, devido à baixa relação água/cimento da mistura.

\subsection{Análise visual superficial}

Destacam-se algumas manifestações verificadas nos traços. No traço BAC.PE, percebeu-se a formação de produtos de cicatrização em fissuras secundárias da amostra, e sua deposição superficial, vide Figura 5.

Como é possível destacar, aparentemente, a limitação das fissuras cicatrizadas decorre da sua abertura máxima. Na fissura principal evidenciada nessa amostra não se percebeu a formação de produtos de cicatrização. Na bibliografia fala-se sobre a cicatrização se limitar a fissuras de menores dimensões (ZHANG et al., 2016; JIANG et al., 2020). Percebeu-se nas amostras que o produto de cicatrização ocorre no formato de placa. A bibliografia afirma que esse formato de placa é atribuído a presença de calcita, produto esperado em soluções bacterianas (SCHWANTES-CEZARIO et al., 2018; ALGHAMRI et al., 2016). Em relação ao traço contendo bactérias em AE, percebeu-se a formação de produtos no interior da fissura, conforme a Figura 6. 

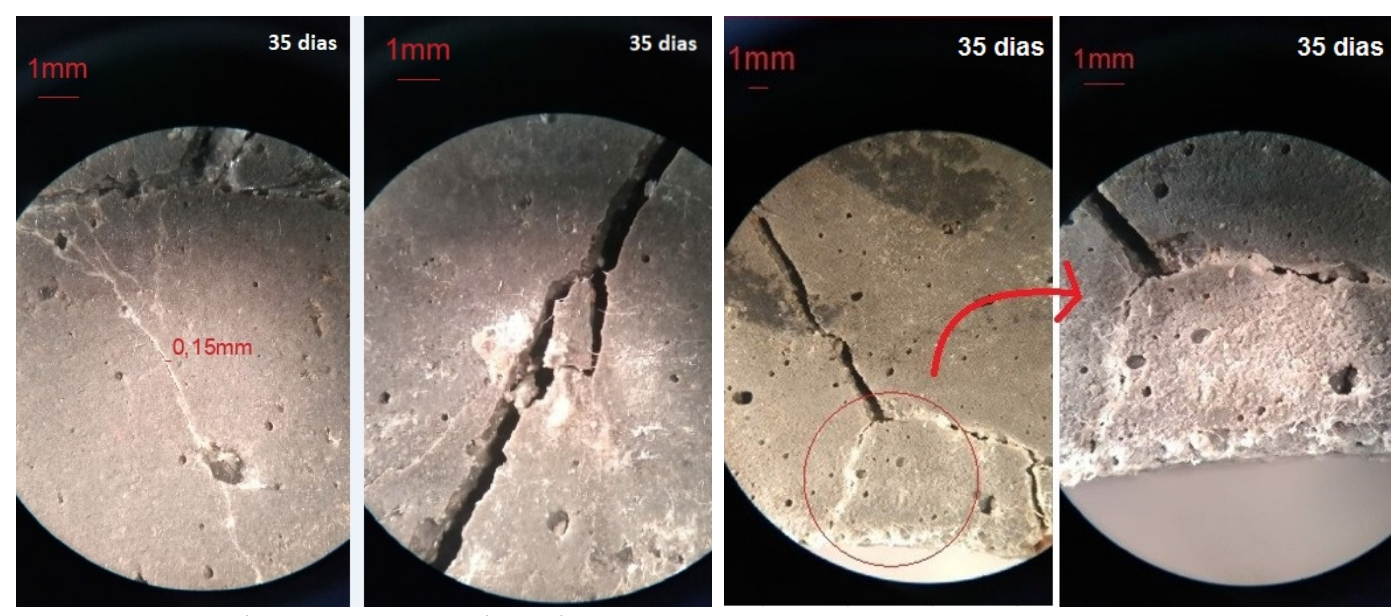

Figura 5. Autocicatrização no traço BAC.PE - Amostra 1.
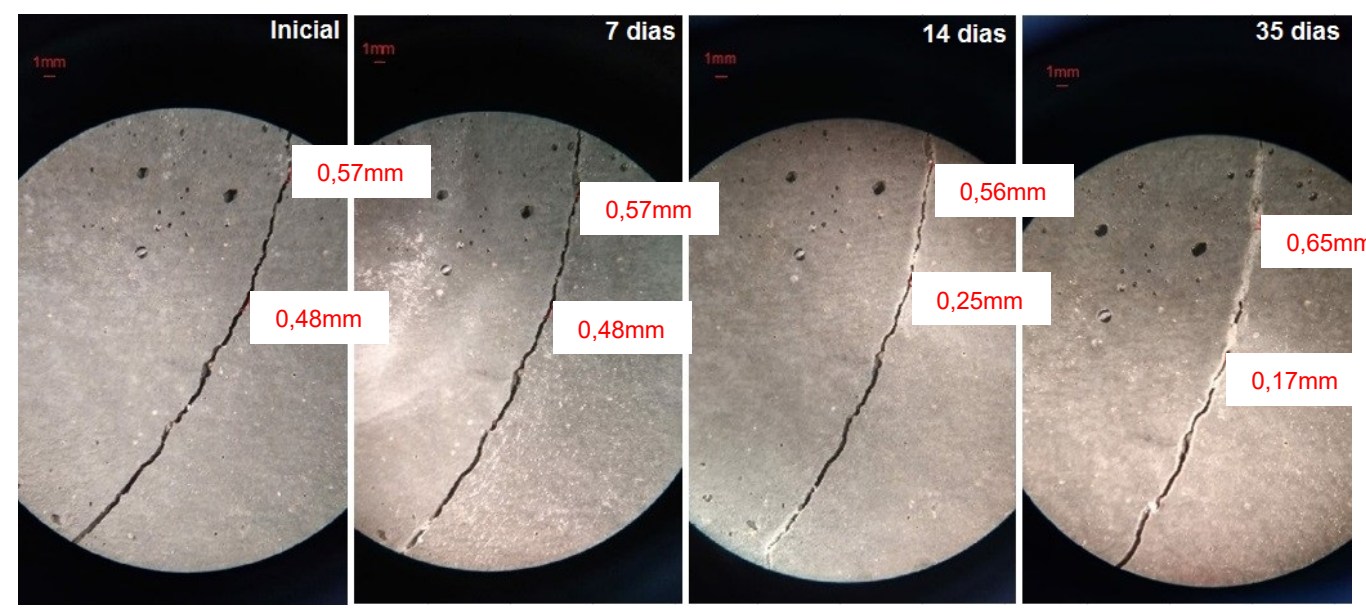

Figura 6. Autocicatrização no traço BAC.AE - Amostra 2.
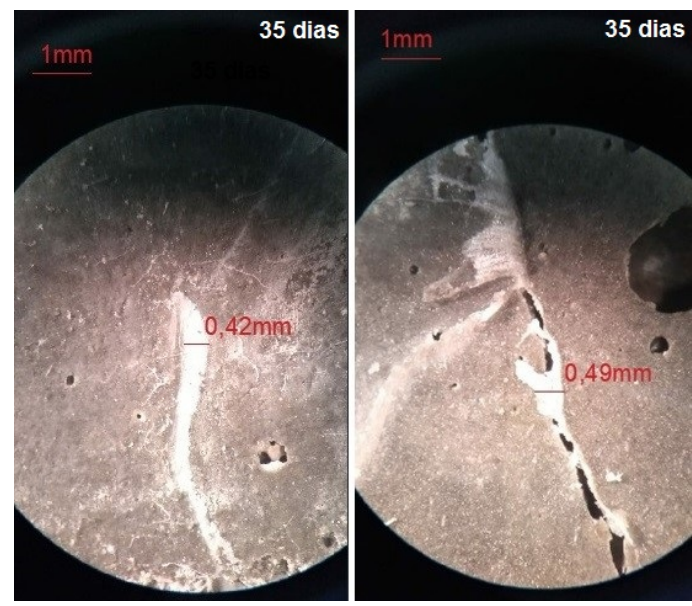

Figura 7. Autocicatrizações no traço BAC.AE - Amostras 3 e 1. 

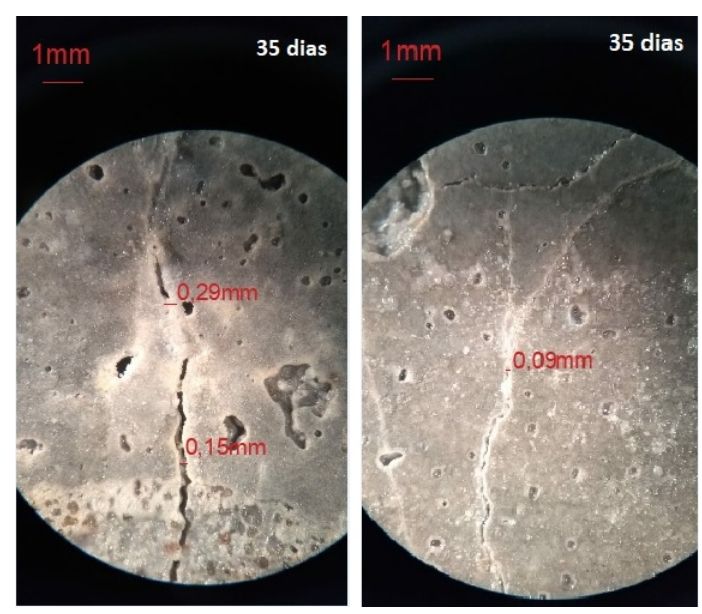

Figura 8. Autocicatrização no traço SS - Amostras 1 e 2.

Houve cicatrização em vários pontos ao longo da fissura, sendo a maior largura de fissura completamente selada de $0,57 \mathrm{~mm}$. Percebeu-se o caráter progressivo da cicatrização, sendo a fissura inicial de $0,48 \mathrm{~mm}$ com apenas $0,17 \mathrm{~mm}$ na idade final, concordando com Zhang et al. (2017). Outra observação que pode ser feita é que a distribuição do produto não foi uniforme na fissura, o que pode decorrer da disponibilidade da perlita no local para a liberação do produto de regeneração e consequente formação de calcita, o que condiz com o estudo realizado por Alghamri et al. (2016).

$\mathrm{Na}$ Figura 7, apresenta-se o traço BAC.AE com cicatrização de 0,42mm e 0,49mm respectivamente. Observa-se que não apenas ocorreu a formação de produto de cicatrização, como sua formação se deu em espessura superior a abertura inicial, indicando depósito na superfície da amostra. Esse tipo de ocorrência é atribuído a presença de calcita, como já citado.

Referente ao traço SS, a Figura 8 apresenta uma fissura com abertura inicial de $0,31 \mathrm{~mm}$ e final de 0,09mm. Também é importante destacar que houve uma cicatrização em placas pontuais em ambas as amostras, visíveis ao microscópio a partir da idade de 14 dias. Isso pode ser atribuído à existência de pequenos poros superficiais que permitem o acúmulo de água, criando assim um ambiente favorável à autocicatrização. No traço SS, a espessura máxima de fissura cicatrizada foi de $0,29 \mathrm{~mm}$, apresentada na amostra 1 .

Por fim, é interessante observar que a cicatrização, em todas as amostras, ocorre prioritariamente de maneira pontual. Esse comportamento se dá, provavelmente, devido à dispersão das cápsulas na estrutura interna das amostras. No traço SS pode ter ocorrido falhas na dispersão do silicato de sódio, o que condiz com apontamentos feitos por Van Tittelboom e de Belie (2013), Ainda, percebeu-se que a cicatrização começa a se formar na parede das fissuras, encaminhando-se gradativamente para o centro, corroborando com o estudo de Al-Tabbaa et al. (2019).

Ao comparar com a bibliografia, é visto que Zhang et al. (2017), recuperaram fissuras de até $0,79 \mathrm{~mm}$ aos 28 dias de cura, sendo esta diferença provavelmente constatada devido aos autores utilizarem outro material regenerante, especificamente, a bactéria Bacillus cohnii encapsulada em perlita e revestida com geopolímero. Da mesma forma, Jiang et al. (2020), ao estudarem o encapsulamento de $B$. cohnii em perlita expandida conseguiram selar fissuras de até $0,4 \mathrm{~mm}$, valor muito próximo aos encontrados no presente trabalho.

Ainda em comparativo com a bibliografia, Van Tittelboom e de Belie (2013), provam que não há linearidade na cicatrização da fissura, conforme apresentado nos resultados. Isto ocorre, pois a cicatrização só acontece se há disponibilidade de material regenerante, sendo assim, onde não há indícios de cicatrização, não há agente regenerante suficiente disponível para que ocorra o fechamento da fissura. A Tabela 2 apresenta o resumo dos resultados obtidos para a espessura máxima cicatrizada em cada amostra do estudo. 
Finalmente, podemos constatar que o traço BAC.AE foi capaz de cicatrizar fissuras com espessuras expressivamente maiores do que ambos os outros traços, uma vez que a maior dimensão selada por ele foi de $0,57 \mathrm{~mm}$, enquanto os traços BAC.PE e SS cicatrizaram $0,16 \mathrm{~mm}$ e $0,29 \mathrm{~mm}$, respectivamente. Dito isso, conclui-se que o traço que apresentou melhor eficiência na análise visual das fissuras foi o traço BAC.AE, devido à sua maior quantidade de fissuras seladas e por apresentar as maiores espessuras cicatrizadas.

\subsection{Microtomografia 3D}

O ensaio de microtomografia 3D foi realizado no Instituto Tecnológico em Ensaios e Segurança Funcional (itt Fuse), na Unisinos. A Figura 9 apresenta os resultados gerados pela microtomografia para o traço BAC.PE. É possível perceber que a PE utilizada na mistura, facilmente detectada pela coloração amarela, encontra-se distribuída de forma regular ao longo da amostra, com apenas alguns pontos com acúmulo de agregado. Esta distribuição é favorável uma vez que ocorram as fissuras, pois haverá uma maior probabilidade de elas encontrarem e romperem cápsulas de $\mathrm{PE}$, liberando o agente cicatrizante. Além disso, apresentam-se vazios no percentual de $11,45 \%$ em proporção ao volume total da amostra ensaiada, valor esse que condiz com os resultados à compressão apresentados anteriormente, uma vez que concretos mais porosos costumam ter resistências mais baixas (YANG; JIANG, 2003).

Tabela 2. Resumo dos resultados.

\begin{tabular}{|c|c|c|}
\hline Traço & Amostra & Espessura máxima cicatrizada \\
\hline \multirow{3}{*}{ BAC.PE } & 1 & $0,16 \mathrm{~mm}$ \\
& 2 & $0,14 \mathrm{~mm}$ \\
& 3 & $0,12 \mathrm{~mm}$ \\
\hline \multirow{3}{*}{ BAC.AE } & 1 & $0,38 \mathrm{~mm}$ \\
& 2 & $0,57 \mathrm{~mm}$ \\
& 3 & $0,42 \mathrm{~mm}$ \\
\hline \multirow{3}{*}{ SS } & 1 & $0,29 \mathrm{~mm}$ \\
& 2 & $0,22 \mathrm{~mm}$ \\
& 3 & Não ocorreu cicatrização \\
\hline
\end{tabular}

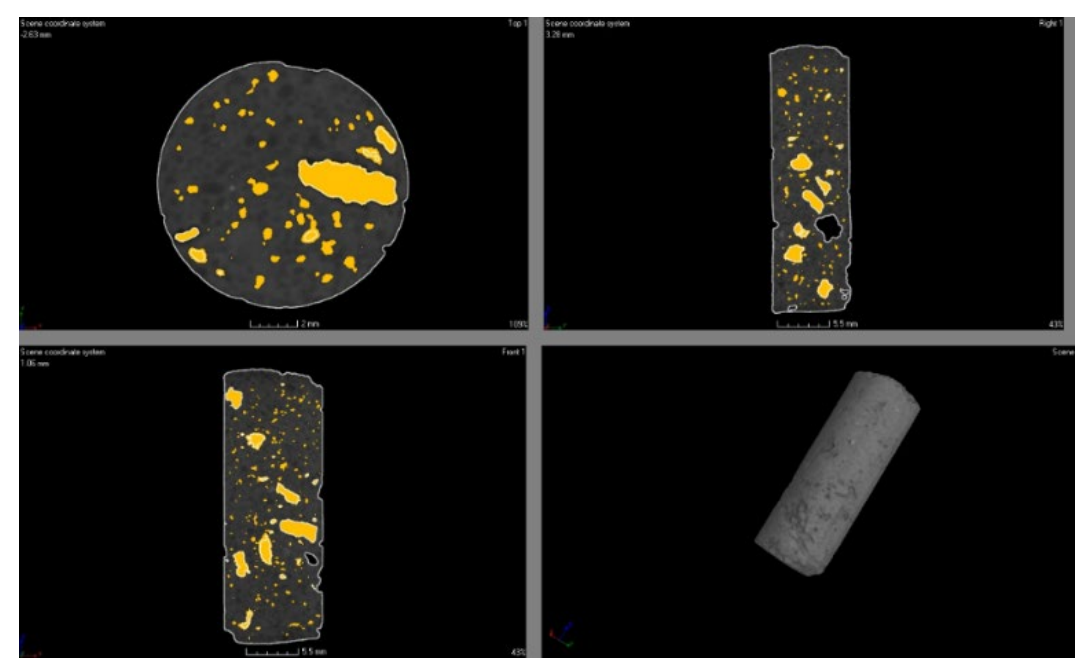

Figura 9. Microtomografia do traço BAC.PE. 


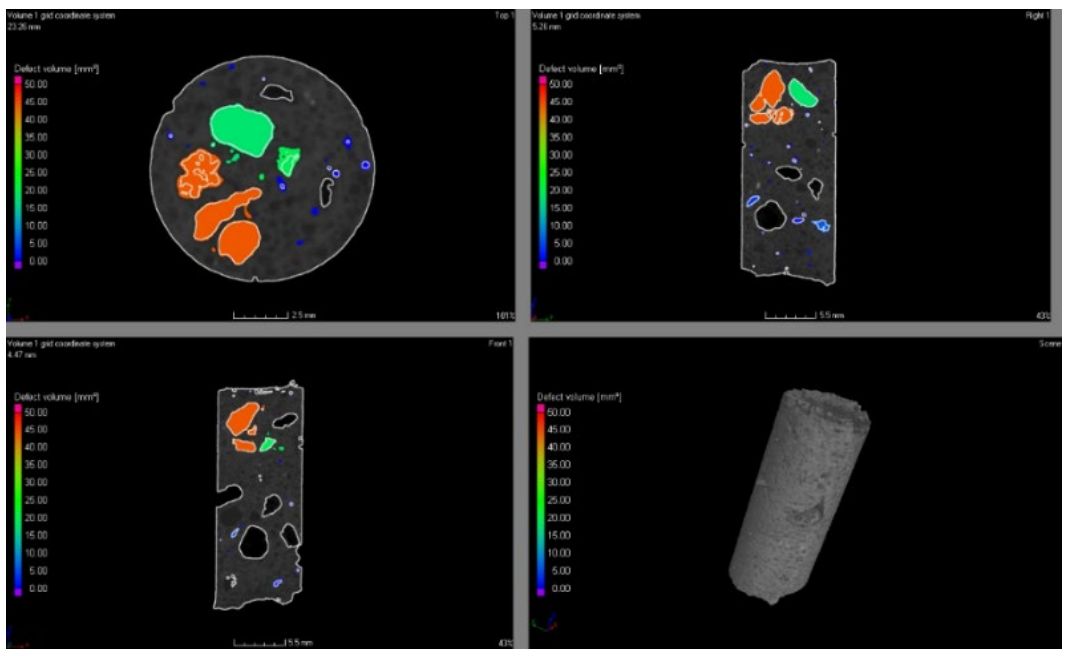

Figura 10. Microtomografia do traço BAC.AE.

É possível observar, na Figura 10, que no traço BAC.AE há uma má distribuição da AE na estrutura interna da amostra ensaiada, sendo a $\mathrm{AE}$ os pontos com diferentes colorações dentro da amostra, o que pode ter impactado na distribuição do agente cicatrizante. O percentual de vazios encontrado para esta amostra ensaiada é de $8,38 \%$ em proporção ao seu volume, o que pode estar relacionado à maior resistência à compressão observada para este traço.

Por fim, a Figura 11, apresenta os resultados da microtomografia para o traço SS, onde é possível observar uma distribuição adequada dos constituintes da mistura ao longo de toda a amostra, situação essa que, assim como apontado anteriormente, é favorável à formação de produto cicatrizante em toda a superfície da argamassa. O percentual de vazios encontrado nesta amostra é de $2,28 \%$ em proporção ao seu volume total.

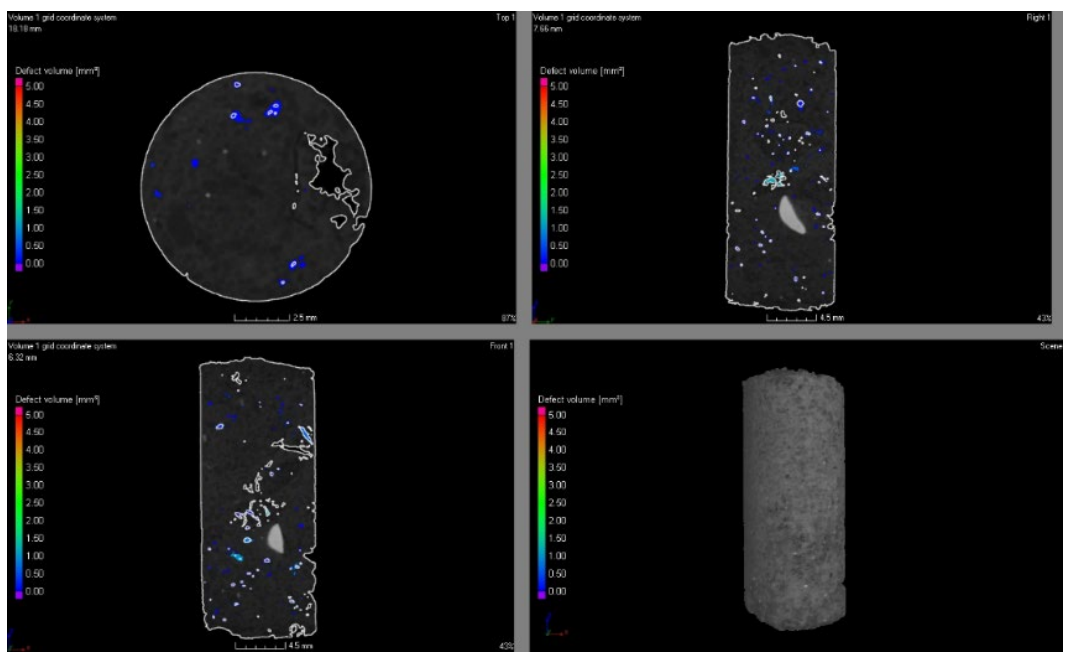

Figura 11. Microtomografia do traço SS.

Sobre a microtomografia do traço SS, é pertinente destacar que a amostra a que se refere não contém agregados leves, e assim, o percentual verificado de vazios é atribuído a falhas na compacidade, a presença de zona de transição e os vazios entre os materiais.

Analisando comparativamente os vazios das três amostras, percebe-se que os dois traços contendo AE e PE apresentaram valores muito superiores, isso pois, mesmo após a impregnação com solução bacteriana a estrutura porosa da PE se manteve, o que resultou nessa identificação 
de vazios. No traço SS, de maior compacidade, percebeu-se índice muito inferior. Sobre isso, cabe citar que não se percebem danos na incorporação do SS diretamente na matriz.

\section{CONCLUSÃO}

O ensaio de resistência mecânica apontou que o traço com melhor desempenho mecânico foi o do traço BAC.AE, composto de solução bacteriana impregnada em AE, que atingiu resistência de 53,1 MPa aos 35 dias, comparado à 42,5 $\mathrm{MPa}$ e 40,4 $\mathrm{MPa}$ referentes aos traços BAC.PE e SS, respectivamente. Além disso, foi também o traço BAC.AE que apresentou maior capacidade de cicatrização quando realizada análise superficial dos CPs, tendo como fissura máxima selada $0,57 \mathrm{~mm}$. Essa espessura é superior às ocorridas nos outros traços, que obtiveram resultados menores, mas ainda assim bastante expressivos e eficazes quanto à cura de microfissuras, ficando em 0,16 mm para o traço BAC.PE e 0,29 $\mathrm{mm}$ para o traço SS.

Também é importante observar que a formação dos agentes cicatrizantes não se deu apenas no interior das fissuras, tendo também ocorrido na superfície das amostras, principalmente no traço SS, pois o mesmo, por não conter cápsulas, torna desnecessária a ocorrência de fissuração para liberar o agente regenerador. Dessa forma, há maior facilidade em concentrar o agente regenerante na superfície da amostra. Em complemento, é necessário ressaltar que a cicatrização das fissuras ocorreu mais pontualmente que ao longo de toda sua extensão.

Através da análise da microtomografia 3D, foi possível verificar o volume e o índice de vazios presente em cada traço analisado no estudo, propiciando assim o entendimento de que os materiais constituintes da argamassa estavam bem dispersos dentro das matrizes cimentícias, o que facilita a atuação dos agentes cicatrizantes ao longo de toda a amostra. Exclui-se aqui o traço BAC.AE, pois a amostra ensaiada para ele estava com problemas de moldagem, não sendo possível observar sua real eficácia. A moldagem é dificultada pela reduzida dimensão da amostra e seu adensamento.

Dessa forma, de posse de todos estes dados, é possível concluir que o traço mais eficiente, de forma geral, foi o traço BAC.AE, possivelmente pelo fato de o mesmo utilizar argila expandida em sua composição e a mesma ser mais resistente que os outros materiais empregados, mantendo os microrganismos presentes mais intactos durante o processo de moldagem.

Do ponto de vista da produção e aplicação em larga escala, no entanto, há benefícios e possibilidade de emprego do traço SS, uma vez que os procedimentos envolvidos na impregnação das cápsulas são eliminados do processo produtivo do concreto. Finalmente, este trabalho mostrou-se satisfatório, podendo obter resultados melhores com idades mais avançadas.

\section{REFERENCIAS}

Associação Brasileira de Normas Técnicas (2005). NBR 13279: Argamassa para assentamento e revestimento de paredes e tetos - Determinação da resistência à tração na flexão e à compressão. Rio de Janeiro.

Associação Brasileira de Normas Técnicas (2015). NBR 5738: Concreto - Procedimento para moldagem e cura de corpos de prova. Rio de Janeiro.

Associação Brasileira de Normas Técnicas (2018). NBR 5739: Concreto - Ensaio de compressão de corpos de prova cilíndricos. Rio de Janeiro.

Associação Brasileira de Normas Técnicas (2014). NBR 6118: Projeto de estruturas de concreto - Procedimento. Rio de Janeiro. 
Associação Brasileira de Normas Técnicas (2003). NBR NM 248: Agregados - Determinação da composição granulométrica. Rio de Janeiro.

Associação Brasileira de Normas Técnicas (2006). NBR NM 45: Agregados - Determinação da massa unitária e do volume de vazios. Rio de Janeiro.

Associação Brasileira de Normas Técnicas (2005). NBR NM 52: Agregado miúdo Determinação de massa específica e massa específica aparente. Rio de Janeiro.

Achal, V., Mukherjee, A., Reddy, M. S. (2011), Effect of calcifying bacteria on permeation properties of concrete structures. Journal of Industrial Microbiology and Biotechnology. 38:1229-1234.

Al-Tabbaa, A., Litina, C., Giannaros, P., Kanellopoulos, A., Souza, L. (2019), First UK field application and performance of microcapsule-based self-healing concrete. Construction and Building Materials. 208:669-685.

Alghamri, R., Kanellopoulos, A., Al-Tabbaa, A (2016), Impregnation and encapsulation of lightweight aggregates for self-healing concrete. Construction and Building Materials. 124:910921.

Carmona Filho, A., Carmona, T. (2013), "Fissuração nas estruturas de concreto". Boletim Técnico ALCONPAT Internacional.

Cappellesso, V. G. (2018), “Avaliação da autocicatrização de fissuras em concretos com diferentes cimentos", Dissertação de Mestrado, Universidade Federal Do Rio Grande Do Sul, p. 279.

Chemrouk, M. (2015), The deteriorations of reinforced concrete and the option of high performances reinforced concrete. Procedia Engineering. 125:713-724.

Gupta, S., Pang, S. D., Kua, H. W (2017), Autonomous healing in concrete by bio-based healing agents - A review. Construction and Building Materials. 146:419-428.

Jonkers, H. M. (2011), Bacteria-based self-healing concrete. Frankfurter Afrikanistische Blätter. $8: 49-79$.

Jonkers, H. M., Thijssen, A. (2010). "Bacteria Mediated Remediation of Concrete Strutures" in: K. van Breugel, G. Ye, Y. Yuan (Eds.), 2nd International Symposium on Service Life Design for Infrastructure, [S. 1.], pp. 833-840.

Krishnapriya, S., Babu, D. L. V., Arulraj, G. P. (2015), Isolation and identification of 60 bacteria to improve the strength of concrete. Microbiological Research. 174:48-55.

Li, V. C., Herbert, E. (2012), Robust Self-Healing Concrete for Sustainable Infrastructure. Journal of Advanced Concrete Technology. 10:207-218. 
Lottermann, A. F. (2013), "Patologias em estruturas de concreto: estudo de caso", Monografia, Universidade Regional do Noroeste do Estado do Rio Grande do Sul, p. 66.

Mehta, P. K., Monteiro, P. J. (2014), "Concreto: microestrutura, propriedades e materiais". IBRACON, São Paulo, Brasil, p. 782.

Pacheco, F. (2020), "Análise da confiabilidade dos mecanismos de autorregeneração do concreto em ambientes agressivos de exposição", Tese de Doutorado, Universidade do Vale do Rio dos Sinos, p. 348.

Patel, P. (2015), Helping Concrete Heal Itself. ACS Central Science. 1(9):470-472.

Pelletier, M. M., Brown, R., Sshukla, A., Bose, A. (2011), "Selfhealing concrete with a microencapsulated healing agent". University of Rhode Island, Kingston, RI, USA.

Ramachandran, S. K., Ramakrishnan, V., Bang, S. S. (2001), Remediation of concrete using microorganisms, ACI Mater. J. 98(1).

Schwantes-Cezario, N., Nogueira, G. S. F., Toralles, B. M. (2017), Biocimentação de compósitos cimentícios mediante adição de esporos de B. subtilis AP91. Revista de Engenharia Civil IMED. 4(2):142-158.

Seifan, M., Samani, A. K., Berenjian, A. (2016), Bioconcrete: next generation of selfhealing concrete, Applied Microbiology and Biotechnology. 100:2591-2602.

Sisomphon, K., Copuroglu, O., Fraaij, A. (2011), Application of encapsulated lightweight aggregate impregnated with sodium monofluorophosphate as a selfhealing agent in blast furnace slag mortar. Heron. 56(1-2):17-36.

Souradeep, G., Kua, H. W. (2016), Encapsulation Technology and Techniques in Self-Healing Concrete. Journal of Materials in Civil Engineering. 25:864-870.

Tittelboom, K. V., De Belie, N. (2013), Self-Healing in Cementitious Materials - A Review. Materials. 6:2182-2217.

Van Breugel, K. (2007). "Is there a market for self-healing cement-based materials?" in: First International Conference on Self Healing Materials, Noordwijk aan Zee (Netherlands), pp. 1-9.

Wang, J., Dewanckele, J., Cnudde, V., Vlierbergue, S. V., Verstraete, W., De Belie, N. (2014), $\mathrm{X}$-ray computed tomography proof of bacterial-based self-healing in concrete. Cement and Concrete Composites. 53:289-304.

Yang, J., Jiang, G. (2003), Experimental study on properties of pervious concrete pavement materials, Cement and Concrete Research. 33:381-386. 